\section{What's in a Word?}

\author{
Marvin L. Birnbaum, MD, PhD
}

Thanks to words, we have been able to rise above the brutes; and thanks to words, we have often sunk to the level of demons. Aldos Huxley Adonis and the Alphabet, 1956

How often misused words generate misleading thoughts.

Herbert Spenser

Principles of Ethics, 1879

Recently, it has been suggested that the title of this journal should be changed to "Prehospital and Disaster Health" or "Emergency Health" or "Health in Crisis", or other similar titles. Similar suggestions have been directed at the title of the World Association for Disaster and Emergency Medicine (WADEM).

There are those who feel that the term "medicine" is not inclusive of their specific discipline, some even believe that their role in the practice of disaster and emergency medicine is excluded by the respective titles. These views are particularly relevant regarding the fact that the delivery of health care during crises or disasters is both multidisciplinary and interdisciplinary. This consideration begs the question as to whether the term "medicine" is inclusive or exclusive of the disciplines, components, and professions involved in disaster and emergency health care. Does "medicine" relate only to physicians or is it inclusive of the entire team rendering care to the sick or injured?

Similar discussions between intensive care physicians, nurses, pharmacists, respiratory therapists, etc. occurred early in the history of the Society of Critical Care Medicine (SCCM). Some believed that critical care medicine was inclusive to the care provided by physicians and did not include the other professions that comprised the critical care team. At the time, the science of critical care medicine was meager, and it was essential that all involved in the care of critically ill patients practiced from the same knowledge base-we learned from each other and developed the evidence base as we practiced together. It was evident and remains today that the science and practice of critical care medicine involves physicians, nurses, respiratory therapists, pharmacists, physical therapists, social workers, chaplains, and more. In order to obtain the best outcomes for critically ill patients, the contributions of the entire of the team are required. For each of the companion disciplines to separate their knowledge, issues, and practice would result in fragmentation and poorly coordinated medical health care of critically ill patients. In keeping with this team model, the Society of Critical Care Medicine did not change its name nor that of its medical journal, Critical Care Medicine. The
SCCM continues to insist that the term "medicine" is inclusive of all of the disciplines involved in the delivery of critical care. Within SCCM, numerous professional groups (nurses, respiratory therapists, surgeons, anesthesiologists, etc.) have developed special professional interest sections to network as well as address issues and concerns relative to their specific profession. Importantly, each of these professions has a significant role in the governance of the SCCM.

There are numerous definitions of the term, "medicine", including:

1. The science and art of preventing, curing, or alleviating disease; ${ }^{1}$

2. The science of practice of the diagnosis, treatment, and prevention of disease; ${ }^{2}$

3. The science of diagnosing, treating, or preventing disease and injury to the body or mind; the branch of this science encompassing treatment by drugs, diet, exercise, and other non-surgical means. ${ }^{3}$

None of these definitions infer that "medicine" applies only to physicians. Thus, it seems that concerns about the use of "medicine" are more of a perception issue than one of language or definition. However, the belief that the term "medicine" is exclusive, could result in fragmentation of the care provided. As in critical care, multiple disciplines comprise disaster medicine including nurses, physicians, doctors, pharmacists, respiratory therapists, engineers, social workers, psychologists, drivers, communicators, coordinators, administrators, etc. There are no professions called medicines or public healths!

It may be helpful to examine this issue using the Basic Societal Functions (BSFs) outlined in the Guidelines for Evaluation and Research espoused by the WADEM and the Task Force on Quality Control of Disaster Management. ${ }^{4}$ The BSFs describe the major functional components of a society. They have been outlined so as to assign functions into groups for the purposes of research and/or evaluation. The BSF of Medical Care and includes all of the elements of health care provided to individual patients regardless of the discipline or profession providing such services. The Medical Care BSF is comprised of many subfunctions that together are responsible for providing the care to the victims of disaster. It includes physicians, nurses, surgeons, technicians, etc.-all working to provide the care of the injured or ill individuals. Each of these disciplines has a role in the care of these victims; each brings a special expertise into this care. The components of the Medical Care BSF are neither inclusive nor exclusive.

However, the Public Health BSF is separated from the Medical Care BSF. This raises the question of exclusivity. 
Public health or perhaps the better term, "population health", functions to protect the health of populations and is not involved with the health of individual patients, except as it involves risks to the population. Should disaster and emergency "medicine" also include the Public Health BSF and all of its components? Together, the Medical Care and Public Health BSF often are referred to as the "Health Sector". Certainly, Public Health and Medical Care BSFs are interdependent and dependent upon each other. They are tightly intertwined. But, so are the BSFs of Water and Sanitation, Food, Shelter and clothing, and so on. However, for research and evaluation purposes, it is necessary to assign each of the societal functions into one BSF. Although some of the issues relating to medical care are distinctly separate from some of those relating to public health. But, for the most part, they both deal with health.

What do we mean when we say "disaster medicine"? Should it be called disaster health? Would the exchange of "health" for "medicine" solve this dilemma? Or is this purely an issue of semantics? Would such an exchange in the title of PDM or WADEM be a more accurate reflection of what is encompassed? Would "health" more accurately describe the interest and scope of practices of its readers and members? Is it worth such a change?

In many ways, the current development of disaster and emergency medicine mirrors that which occurred in the development of critical care medicine. Disaster and emergency medicine currently is where critical care medicine was in the 1980s and 1990s. The scope of disaster and emergency medicine is so broad and entails so many professions that it is paramount that we learn from each other and collaborate to define our basic competencies. We must share our knowledge and develop the minimal competencies required to certify that we are qualified to practice in this discipline.

My greatest concern is that the arguments and posturing over semantics will interfere with the development of the science of Disaster and Emergency Medicine. Although these discussions are healthy and should continue, we cannot let them divert us from the real goal of developing our science. Clearly, each of the component disciplines of Disaster and Emergency Medicine have issues related to the practice of Disaster and Emergency Medicine, and these must be addressed within the specific component disciplines. In recognition of these important needs, the WADEM has encouraged the development of professionspecific sections. The Nursing Section is establishing the role of nurses in the practice of Disaster and Emergency Medicine. In collaboration with other nursing organizations, the Nursing Section is beginning the process of developing nursing-specific competencies. Other specific components of Disaster and Emergency Medicine, i.e., population health practitioners, dentists, veterinarians, administrators, coordinators, pathologists, pharmacists, engineers, and other disciplines also will form sections. But, in the end, all of us must come together to prevent disease and injuries and to treat those stricken by crises. It's lonely and frightening out there when the team is not with us. Please, let us move forward rather than concentrate on what is meant by a single word.

Lord, make my words sweet and reasonable. Some day I may bave to eat them.

Paddy Ashdown

The Observer, 1998

\section{References}

1. Thatcher VS (ed): The New Webster Dictionary of the English Language, Chicago: Consolidated Book Publishers, 1971. p 525.

2. Thompson D: The Concise Oxford Dictionary of Current English, 9th ed, Oxford: Clarendon Press, 1995, pp 846-847.
3. Picket JP, Pritchard DR, Leonesio C (eds): The American Heritage College Dictionary, 4th ed, Boston: Houghton Mifflin Co., 2002, p 862.

4. Sundnes KO, Birnbaum ML (eds), and the Task Force for Quality Control of Disaster Management: Health disaster management: Guidelines for evaluation and research in the Utstein style. Prehosp Disast Med 2003;17(s3). 